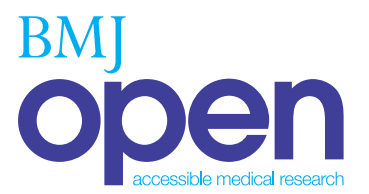

\title{
The correlation between third-trimester maternal and newborn-serum 25-hydroxy-vitamin D in a selected South Australian group of newborn samples
}

Sunethra Devika C Thomas, Andrew N Fudge, Malcolm Whiting, Penelope S Coates

To cite: Thomas SDC, Fudge AN, Whiting $\mathrm{M}$, et al. The correlation between third-trimester maternal and newborn-serum 25-hydroxy-vitamin D in a selected South Australian group of newborn samples. BMJ Open 2011;1:e000236. doi:10.1136/bmjopen-2011000236

- Prepublication history for this paper is available online. To view these files please visit the journal online (http:// bmjopen.bmj.com).

Received 28 June 2011 Accepted 9 August 2011

This final article is available for use under the terms of the Creative Commons Attribution Non-Commercial 2.0 Licence; see http://bmjopen.bmj.com

Department of Chemical Pathology, SA Pathology, Adelaide, South Australia, Australia

Correspondence to Dr Devika Thomas; devika. thomas@health.sa.gov.au

\section{ABSTRACT}

Background: Although vitamin $D$ insufficiency is prevalent in the community, only a few populationbased studies have measured serum 25-hydroxyvitamin $D(250 \mathrm{HD})$ levels during pregnancy and in newborns. Maternal vitamin $D$ deficiency has been linked to pregnancy complications, as well as hypocalcaemia and rickets in the newborn. Here, the authors report third-trimester maternal and newbornserum 250HD concentrations in 101 neonates whose serum samples were sent for testing.

Methods: The newborn 250HD levels were correlated with the third-trimester maternal serum $250 \mathrm{HD}$ levels using a least-square regression analysis. All samples were measured using an enzyme immunoassay (EIA). Ten randomly selected newborn serum samples were also measured using liquid chromatography/tandem mass spectrometry LC-MSMS, and correlated with the EIA method.

Results: Out of 99 mothers of the newborns, only 19 , 42 and 68 had their 250HD level measured in the first, second and third trimester respectively. The mean maternal age was 30 years, while the mean maternal third-trimester $250 \mathrm{HD}$ concentration was $48 \mathrm{nmol} / \mathrm{l}$. Of the newborns, $53 \%$ were female, and $85 \%$ were term deliveries. The mean newborn-serum 250HD was $68 \mathrm{nmol} / \mathrm{l}$. Neonatal $250 \mathrm{HD}$ was related to maternal third-trimester levels measured by EIA $(r=0.3$; newborn $250 \mathrm{HD}=0.42$ (maternal $250 \mathrm{HD}$ ) +44.2 ; $\mathrm{p}=0.02)$. EIA and LC-MSMS concentrations for newborns correlated significantly over a range between 20 and $103 \mathrm{nmol} / \mathrm{l}$ by EIA ( $\mathrm{r}=0.9$; EIA=1.04 (LCMSMS)+10.1; $p<0.00$ (slope); $p=0.18$ (intercept)). The mean 250HD concentration in women who suffered pre-eclampsia and premature rupture of membranes were 45 and $39 \mathrm{nmol} / / \mathrm{l}$ respectively.

Conclusions: Newborn-serum 250HD concentrations depend on the maternal circulating plasma $250 \mathrm{HD}$ level at least during the third trimester. Neonatal 250HD levels obtained by EIA correlated well with LC-MSMS. Although the EIA values for neonates were greater than LC-MSMS values, this difference was not statistically significant.

\section{ARTICLE SUMMARY}

Article focus

n There is evidence that maternal vitamin D status affects fetal and neonatal development.

- Despite the evidence, testing for vitamin D during pregnancy is not offered to many women in our community.

n We hypothesise that the maternal vitamin $D$ status especially the 3 rd trimester maternal serum levels determines the neonatal vitamin $D$ status.

\section{Key messages}

- Despite National Guidelines, women in the third trimester of pregnancy are vitamin $\mathrm{D}$ deficient.

- Maternal vitamin D status determines the neonatal vitamin $D$ status.

- Women with very low levels of vitamin D may be more likely to develop pregnancy and birth comlications.

\section{Strengths \& limitations}

Strengths

- Access to 100 newborn samples from a teaching hospital.

- Validation of enzyme immunoassay with HPLCmass spectrometry for neonatal vitamin $D$.

\section{Limitations}

- Numbers of women with pregnancy and birth complications are too small to make a strong statement regarding direct effects of vitamin $\mathrm{D}$.

- No follow-up data available for the neonates (ie, developemental milestones etc).

\section{INTRODUCTION}

Maternal vitamin D deficiency is a common public-health problem. ${ }^{1}{ }^{2}$ Individuals with deeply pigmented skin and those with minimal skin exposure to sun are considered 
to be particularly at risk of vitamin $\mathrm{D}$ deficiency. ${ }^{3}$ During intrauterine development, the fetus accumulates about $30 \mathrm{~g}$ of calcium from the maternal circulation, and during lactation, a further $280-400 \mathrm{mg}$ /day calcium is secreted into the milk. ${ }^{4}$ This results in an increased demand for calcium in the mother, so it is important that adequate vitamin $\mathrm{D}$ be available to ensure efficient intestinal absorption of calcium.

Vitamin D deficiency in pregnancy has been shown to lead to significant pregnancy complications. Maternal complications include decreased weight gain, ${ }^{5}$ hypertension in pregnancy and pre-eclampsia. ${ }^{1}$ In the newborn, maternal vitamin D deficiency has been linked to hypocalcaemia, low birth weight, ${ }^{6}$ poor weight gain, impaired development and rickets. ${ }^{7}$ Although no health benefits have been associated with vitamin D supplementation during pregnancy, ${ }^{8}$ current evidence suggests that deficiency may be an independent risk factor for pregnancy and birth complications. ${ }^{1}$

A recent revision of Perinatal Guidelines of South Australia $^{9}$ recommends the measurement of serum vitamin $\mathrm{D}$ in all at-risk women during their first antenatal visit. At-risk women are defined as all women who routinely wear head scarves, darker-skinned women, newly arrived migrants and anyone who is housebound. If the serum 25-hydroxy-vitamin D (25OHD) is $<60 \mathrm{nmol} / \mathrm{l}$, the recommendation is to treat them with $1000 \mathrm{U}$ of vitamin D per day. 25OHD measurements are repeated at subsequent visits to monitor progress. The rationale of this protocol is to prevent vitamin D deficiency in the newborn.

The following study was aimed at examining the relationship between concentrations of $25 \mathrm{OHD}$ in maternal serum and newborn.

\section{METHOD}

This study was approved by the Royal Adelaide Hospital Research Ethics Committee (protocol number 090901). One hundred and one consecutive neonatal serum samples were received from a tertiary hospital for 25OHD analysis. Maternal data were obtained from the laboratory database. Noenatal samples were from heel-prick capillary blood samples collected for newborn screening tests during a 3-month period (November, December and January). These values were correlated with the mothers' serum 25OHD measurements collected during the thirdtrimester using regression analysis. There were two sets of twins in the neonatal group, and there were 99 maternal records. Any other maternal serum vitamin D concentrations which were measured during pregnancy were also obtained from the database. The first-trimester measurement has been made in association with antenatal screening tests. However, a proportion of women had a third-trimester 25OHD measurement requested by their general practitioner, and this was either the first during the pregnancy or a follow-up to a previous measurement in the first or the second trimester. All serum measurements were made using an enzyme immunoassay (Immuno Diagnostic Systems, Scottsdale, Arizona). Serum vitamin D was also measured in 10 randomly selected neonatal specimens using an LC/MSMS method (Applied Bio Systems) in order to verify the immunoassay method for neonatal samples.

\section{RESULTS}

The ethnicity of the mother was recorded for 66 women. Of these, 23 were Asian, 15 Middle Eastern, 12 Caucasian, nine Indian and seven African. The mean maternal age was 29.6 years. First-trimester weight was available for 31 mothers, and the mean weight was $64.6 \mathrm{~kg}$ (SD 10.8). Eighty-five infants were delivered at term and 14 infants preterm. Two deliveries were not dated. Spontaneous vaginal delivery was recorded in 48 cases, instrumental delivery in 22, elective caesarean sections in 12 and emergency caesarean sections in 16; the mode of delivery was unknown for 2. Maternal complications recorded were premature rupture of membranes $(\mathrm{n}=10)$, pre-eclampsia $(\mathrm{n}=7)$, postpartum haemorrhage $(n=4)$, ante-partum haemorrhage $(n=3)$, oligohydramnios $(n=1)$ and cholestasis $(n=1)$. Gestational diabetes was reported in three women. Neonatal complications recorded were breach presentation $(n=5)$, shoulder dystocia $(n=4)$, small for gestational age $(n=3)$, neonatal jaundice $(n=3)$ and congenital laryngomalacia $(n=1)$.

For 99 mothers of the 101 neonates, serum 25OHD was measured in the first trimester, second trimester and third trimester in 19, 42 and 68 women respectively. Twenty-eight women had at least two measurements during pregnancy. All 28 had a $25 \mathrm{OHD}$ level below the recommended $60 \mathrm{nmol} / 1 ;{ }^{9}$ only 12 achieved a subsequent measurement above $60 \mathrm{nmol} / \mathrm{l}$. The mean serum $25 \mathrm{OHD}$ in the first, second and third trimesters was $32 \mathrm{nmol} / 1,33 \mathrm{nmol} / 1$ and $44 \mathrm{nmol} / 1$ respectively (table 1). Table 2 shows the mean third-trimester serum 25OHD for the mothers and neonates. During the third trimester, $78 \%$ of the women had a vitamin $\mathrm{D}$ level of $<60 \mathrm{nmol} / \mathrm{l}$. The goal recommended by the Perinatal

Table 1 Maternal serum vitamin $D$ concentrations and the percentages with levels $<25,50$ and $60 \mathrm{nmol} / \mathrm{l}$ for each trimester

\begin{tabular}{lccr}
\hline & $\begin{array}{l}\text { First } \\
\text { trimester }\end{array}$ & $\begin{array}{l}\text { Second } \\
\text { trimester }\end{array}$ & $\begin{array}{l}\text { Third } \\
\text { trimester }\end{array}$ \\
\hline No & 19 & 42 & 68 \\
Mean (SD), & $32(15.6)$ & $33(17.6)$ & $48(20.1)$ \\
nmol/l & & & \\
Median & 30 & 30 & 46 \\
Min-max & $8-57$ & $6-81$ & $14-105$ \\
$\begin{array}{l}\text { Percentage } \\
<25 \text { nmol/l }\end{array}$ & 32 & 40 & 12 \\
$\begin{array}{l}\text { Percentage } \\
<50 \text { nmol/l }\end{array}$ & 74 & 79 & 56 \\
Percentage & 100 & 95 & 78 \\
$<60$ nmol/l & & & \\
\hline
\end{tabular}


Table 2 Mean serum 25OHD in mothers (third trimester) and neonates

\begin{tabular}{lcll}
\hline & $\begin{array}{l}\text { No } \\
\text { analysed }\end{array}$ & $\begin{array}{l}\text { Mean } \\
\text { (nmol/I) }\end{array}$ & SD \\
\hline Uncomplicated & 57 & 47 & 19.3 \\
$\begin{array}{l}\text { Pre-eclampsia } \\
\begin{array}{l}\text { Premature rupture } \\
\text { of membranes }\end{array}\end{array}$ & 7 & 45 & 11.1 \\
All neonates & 9 & 39 & 16.1 \\
\hline
\end{tabular}

Practice Guidelines of South Australia ${ }^{9}$ is $60 \mathrm{nmol} / \mathrm{l}$; therefore $78 \%$ of the women were vitamin $\mathrm{D}$ deficient or insufficient in the third trimester.

The mean 25OHD in the neonates was $68 \mathrm{nmol} / 1$ (17 to 177$)$. Severe deficiency $(<25 \mathrm{nmol} / 1)$ was detected in $4 \%$, mild deficiency $(<50 \mathrm{nmol} / \mathrm{l})$ in $33 \%$ and normal levels $(>50 \mathrm{nmol} / 1)^{10}$ in $63 \%$.

The third-trimester maternal serum 25OHD and neonatal 25OHD were correlated $(\mathrm{r}=0.08 ; \mathrm{p}=0.02$; newborn $25 \mathrm{OHD}=(0.4175$ maternal $25 \mathrm{OHD})+44.234)$ as shown in figure 1 . No relationship was found between neonatal 25OHD and maternal age.

Regression analysis of neonatal 25(OH)D measured using enzyme immunoassay and LC/MS-MS showed a good correlation between the methods $(\mathrm{r}=0.9$; $\mathrm{p}<0.001$; enzyme immunoassay $=1.04(\mathrm{LC} / \mathrm{MS}-\mathrm{MS})+10.1)$.

\section{DISCUSSION}

The women in our study were of mixed ethnic origin, with a large proportion of migrants, many of whom have dark skin and wear traditional dress, leading to lower vitamin $\mathrm{D}$ production in the skin. These factors are well recognised as risk factors for vitamin D deficiency. However, the numbers in each group were too small for a separate analysis.

Despite the perinatal guidelines for the diagnosis and correction of vitamin D deficiency in pregnancy, only

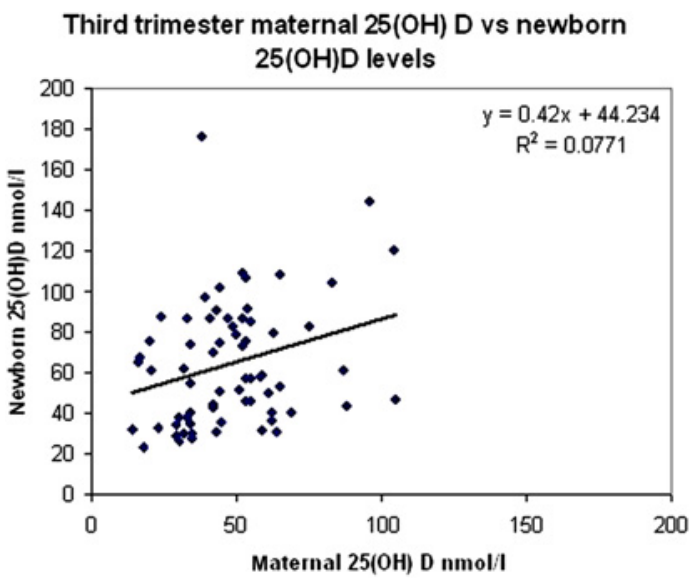

Figure 1 Third trimester maternal 25(OH)D versus newborn $25(\mathrm{OH}) \mathrm{D}$ concentration. $\mathrm{N}=68 ; \mathrm{r}=0.28$.
$19 \%$ of this group of mothers had their serum vitamin D measured in the first trimester. As many as $78 \%$ were 25OHD-deficient during the 3rd-trimester. Only $68 \%$ of the women had their vitamin $\mathrm{D}$ measured in the third trimester. However, the average serum 25OHD for this group of women gradually rose from the first to the third trimester, perhaps owing to supplementation. This suggests that more than $78 \%$ of the women may have been vitamin $\mathrm{D}$ deficient during the first trimester. All third-trimester samples were collected in spring (September to November), and a small seasonal influence cannot be discounted. The rise in $25 \mathrm{OHD}$ with advancing pregnancy may be a natural phenomenon similar to the rise in steroid hormones. The mean serum 250HD during the third trimester was $48 \mathrm{nmol} / \mathrm{l}$, which is below the desirable limit of $60 \mathrm{nmol} / \mathrm{l}$. Measurement of vitamin $\mathrm{D}$ during the first trimester may have been beneficial because this may have allowed the commencement of supplementation earlier to enable serum levels to normalise by third trimester. The incidence of preeclampsia in this group was $7 \%$, which is comparable with the $5-7 \%$ incidence in all pregnancies. ${ }^{11}$

A recent finding suggested that the factors associated with maternal vitamin D deficiency were maternal birthplace outside Australia, dark-skin prototype, wearing a veil and younger maternal age. ${ }^{12}$ Our cohort consisted of a large proportion of immigrants from multiple ethnic backgrounds, and this may have contributed to the prevalence of vitamin $\mathrm{D}$ deficiency.

Neonatal serum 250HD concentration was related to third-trimester maternal vitamin D level. However, some women may have been receiving supplementation closer to delivery date, and thus may have had higher serum levels without a rise in fetal stores. The relationship may have been more significant if vitamin D levels were measured on the day of delivery. ${ }^{2}$ A significant percentage of neonates were vitamin $\mathrm{D}$ deficient at birth $(37 \%)$. This relates to the high prevalence of maternal vitamin $\mathrm{D}$ deficiency. ${ }^{12}$

There was a good correlation between the enzyme immunoassay and LC-MS/MS for the measurement of neonatal vitamin $\mathrm{D}$, suggesting that immunoassay is a valid method of neonatal vitamin $D$. In the samples tested the enzyme immunoassay measured higher values compared with the LC-MSMS method, but this difference was not statistically significant. There is one report in which neonates can have significant concentrations of the 3-epimer of 25OHD in serum, and this form of 250HD may not be measured by different assays ${ }^{13}$ leading to a variability between results obtained from various assays.

Recognition of risk factors and early detection of vitamin D deficiency, and supplementation with vitamin $\mathrm{D}$ to achieve reasonable serum levels during pregnancy, are important in order to prevent neonatal vitamin D deficiency and related complications. Perinatal Practice Guidelines proposed by the government do not appear to be used widely. This may also reflect on 
the women not seeking general practitioner or obstetric consultation during early pregnancy. Therefore, publiceducation campaigns may be required through community organisations and migrant resource centres.

Correction notice The "To cite: ..." information and running footer in this article have been updated with the correct volume number (volume 1).

Funding This research received no specific grant from any funding agency in the public, commercial or not-for-profit sectors.

Competing interests None.

Ethics approval Ethics approval was provided by the Royal Adelaide Hospital Research Ethics Committee.

Contributors All authors contributed equally to the conception, data collection and data analysis as well as the manuscript writing and editing.

Provenance and peer review Not commissioned; externally peer reviewed.

Data sharing statement No data is available.

\section{REFERENCES}

1. Bodnar LM, Catov JM, Hyagriv NS, et al. Maternal vitamin D deficiency increases the risk of preeclampsia. J Clin Endocrinol Metab 2007;92:3517-22.

2. Nicolaidou P, Hatzimastamatiou Z, Papadopoulou A, et al. Low vitamin D status in mother-newborn pairs in Greece. Calcif Tissue Int 2006;78:337-42.
3. van der Meer IM, Karamali NS, Boeke AJ, et al. High prevalence of vitamin $D$ deficiency in pregnant non-Western women in The Hague, Netherlands. Am J Clin Nutr 2006;84:350-3.

4. Kovacs CS. Calcium and bone metabolism in pregnancy and lactation. J Clin Endocrinol Metab 2001;86:2344-48.

5. Parr JH, Ramsay I. The presentation of osteomalacia in pregnancy. Case report. Br J Obstet Gynaecol 1984;91:816-18.

6. Maninion AC, Gray-Donald K, Koski KG. Association of low intake of milk and vitamin $\mathrm{D}$ during pregnancy with decreased birth weight. CMAJ 2006;174:1273-7.

7. Robinson $\mathrm{PD}$, Hogler $\mathrm{W}$, Craig ME, et al. The re-emerging burden of rickets: a decade of experience from Sydney. Arch Dis Child 2006; $91: 564-8$.

8. Institute of Medicine. Dietary Reference Intakes for Calcium and Vitamin D. http://www.iom.edu/Reports/2010/Dietary-ReferenceIntakes-for-calcium-and-vitamin-D.aspx (accessed 28 Jul 2011).

9. Perinatal Practice Guidelines. http://www.health.sa.gov.au/PPG (accessed 15 Sep 2009)

10. Working Group of the Australian and New Zealand Bone and Minera Society, Endocrine Society of Australia and Osteoporosis Australia. Vitamin D and adult bone health in Australia and New Zealand: a position statement. Med J Aust 2005;182:281-5.

11. Esplin MS, Fausett MB, Fraser A, et al. Paternal and maternal components of the predisposition to preeclampsia. N Engl J Med 2001;344:867-72.

12. Bowyer L, Catling-Paull C, Diamond T, et al. Vitamin D, PTH and calcium levels in pregnant women and their neonates. Clin Endocrinol (Oxf) 2009;70:372-7.

13. Singh RJ, Taylor RL, Reddy GS, et al. C-3 epimer can account for a significant proportion of total circulating 25 -hydroxyvitamin $D$ in infants, complicating accurate measurement and interpretation of vitamin D status. J Clin Endocrinol Metab 2006;91:3055-61. 